\title{
Stakeholder Participation for the Purpose of Helping Ensure Evaluation Validity: Bridging the Gap Between Collaborative and Non-collaborative Evaluations
}

\author{
PAUL R. BRANDON
}

\begin{abstract}
Collaborative evaluations, in which program stakeholders participate extensively, typically are conducted for the primary purpose of enhancing the use of evaluation findings, and non-collaborative evaluations, in which stakeholders do not participate extensively, typically are conducted for the primary purpose of generating valid findings. This article shows how the gap can be bridged between these two types of evaluations. The article synthesizes, and elaborates on, a small body of recent research that showed that consider-

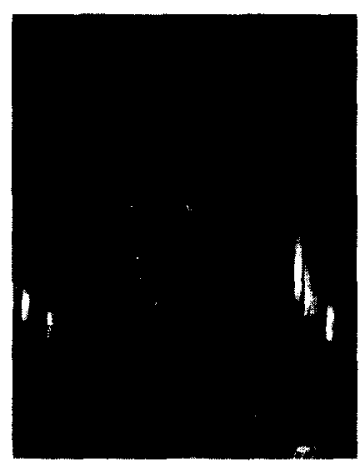

Paul R. Brandon able interaction with stakeholders during the evaluation of small education programs helped achieve the raison d'etre of non-collaborative evaluations-that is, to enhance validity. It is also shown that theories and methods of stakeholder participation for the purpose of enhancing validity, which by and large have been ignored in the collaborative evaluation literature, can improve the quality of collaborative studies.
\end{abstract}

\section{INTRODUCTION}

The collaboration of evaluators with program stakeholders for the purpose of improving educational program evaluations began to be studied widely in the 1970 s, when citizen participation in educational evaluation was encouraged (Smith, 1983). Since then, researchers have developed several approaches for guiding this collaboration. The two collaborative approaches most commonly applied to the evaluation of education programs in the United

Paul R. Brandon - Curriculum Research \& Development Group, University of Hawaii at Manoa, 1776 University Avenue, UHS2-211 Honolulu, HI 96822; Tel: (808)956-4928, Fax: (808)956-4933; E-mail: brandon@hawaii.edu.

American Journal of Evaluation, Vol. 19, No. 3, 1998, pp. 325-337. All rights of reproduction in any form reserved. ISSN: 1098-2140 Copyright (C) 1998 by American Evaluation Association. 
States and Canada have been stakeholder-based evaluation (SBE) (e.g., Bryk, 1983; Donmoyer, 1990; Henry, Dickey, \& Areson, 1991; Tovar, 1989), in which stakeholders are involved somewhat in the beginning and ending phases of evaluations, and practical participatory evaluation (PPE) (e.g., Cousins \& Earl, 1992, 1995), in which stakeholders are heavily involved as evaluation partners in all evaluation phases. ${ }^{1}$

SBE was the first collaborative approach to be widely studied, and PPE is one of the most recent. Evaluators using either of these approaches involve stakeholders for the practical purpose of improving the use of evaluation findings (Bryk, 1983; Cousins, Donohue, \& Bloom, 1996, 1997; Cousins \& Earl, 1992, 1995; Cousins \& Whitmore, 1997). In education settings, both stakeholder-based and participatory evaluators seek to involve administrators, project managers or curriculum coordinators and, in the evaluations of small programs or projects, faculty or operational staff who will help achieve the purpose of enhancing the use of evaluation findings.

The purpose of collaborative evaluations and the extent of stakeholder participation in them typically differs notably from non-collaborative evaluations. Evaluators using non-collaborative approaches focus primarily on the epistemological purpose of generating "valid knowledge concerning program functioning and effects" (Cousins \& Whitmore, 1997, p. 8). These researchers also note that extensive stakeholder participation does not occur: "Stakeholders are relegated to the role of data source, though on occasion [they] may be consulted for input" (Cousins \& Whitmore, 1997, p. 9).

However, as can be seen in four recent research studies on stakeholder participation in evaluation (Brandon, in press; Brandon \& Higa, 1998; Brandon, Lindberg, \& Wang, 1993; Brandon, Newton, \& Harman, 1993), the distinction between collaborative and non-collaborative evaluations is not always clear. Although the evaluations described in these four studies had characteristics of collaborative approaches, in that program stakeholders in all four participated in significant ways during the beginning or ending phases of evaluations, the evaluations examined in these studies also had characteristics of the non-collaborative approach, in that their primary focus was on collecting and reporting valid findings.

The purposes of this article are to show how these four research studies bridge the gap between collaborative and non-collaborative evaluation and to draw implications of these studies for both approaches. Highlights of the four "bridge studies" are provided to show that evaluator-stakeholder interaction enhanced evaluation validity and that their purposes and methods can help improve the quality of future SBE or PPE evaluations.

\section{INVOLVING STAKEHOLDERS TO ENHANCE VALIDITY}

In the four recent studies highlighted in this article, stakeholders participated for the purpose of enhancing validity. By validity, it is meant here that adequate and appropriate inferences (Messick, 1989, 1995) are made from data collected and reported in evaluations. This psychometric definition of validity is essentially the same as that given in the standards developed by the Joint Committee on Standards for Educational Evaluation (1994, p. 145), which stipulate that validity is an issue of the "soundness or trustworthiness of the inferences that are made from the results of the information gathering process" (see also Carey \& Smith, 1992; Owston, 1986; Rogers, 1995).

Inferences should be construct valid. In the psychometric literature, construct validity is a concept that recently has come to subsume all aspects of validity, including (among others) 
instrument content, the technical quality of instruments or data-collection procedures, and the extent to which inferences from data do not have adverse social consequences (Messick, 1989, 1995; Shepard, 1993). ${ }^{2}$

Avoiding threats to the construct validity of inferences made in program evaluations is an important challenge to evaluators. The key threats to construct validity discussed in the psychometric literature are construct-irrelevant variance and construct underrepresentation (Messick, 1989). Construct-irrelevant variance occurs when data are collected on constructs that are irrelevant to the stated purpose of the data collection, and construct underrepresentation occurs when data incompletely address the intended construct.

Both threats to validity, which together might be called construct misrepresentation, ${ }^{3}$ have obvious implications for program evaluators, collaborative and non-collaborative alike. When examining program implementation, for example, invalidity due to construct-irrelevant variance is likely to occur when evaluators examine program aspects that are not intended to be implemented, and invalidity due to construct underrepresentation is likely to occur when evaluators fail to consider key characteristics of implementation such as depth and breadth.

To avoid construct misrepresentation in evaluation, evaluators need to ensure that they have a sufficient level of understanding of the programs they evaluate. It is most important to have this understanding in the beginning phases of cvaluations, when studies are formed, and in the ending phases, when findings are summarized and conclusions are drawn. In the beginning phases, evaluators' understanding of programs should be sufficient to ensure that evaluations are based on valid needs and that the questions that evaluations are intended to answer do not misrepresent program implementation, outcomes, or context (i.e., the "program constructs" which evaluations are commissioned to address). In the ending phases of studies, evaluators' understanding of programs must be at a level sufficient for ensuring that their interpretation of findings is well informed. For example, if they know too little about the intricacies of program administration, their recommendations for program revisions might be inappropriate. Similarly, if they do not know how well a program should perform for it to be considered successful, data interpretation might go awry.

For evaluators to understand programs sufficiently well to conduct valid studies, they often need the assistance of program experts. Cognitive psychologists (e.g., Glaser \& Chi, 1988) and expert-systems researchers (e.g., Hoffman, 1994) have shown that experts not only have factual and practical knowledge unknown by novices but also have knowledge of patterns and themes of which novices are unaware. Furthermore, experts can simplify complex problems, identify which information is relevant to decisions, and effectively communicate their expertise to non-experts (Shanteau, 1988).

Many program stakeholders are program experts. As Huberman and Cox said, "The evaluator is like a novice sailor working with yachtsmen who have sailed these institutional waters for years, and know every island, reef and channel" (1990, p. 165). Stakeholders can help improve evaluators' understanding of programs. By tapping stakeholders' expertise, evaluators are not constrained to using the limited program expertise that they have before beginning an evaluation or that they gain on their own during the course of a study.

The four studies discussed in this article collectively show an approach that can be used to help ensure that evaluators' understanding of programs is sufficient for promoting evaluation validity. Because of the overlap between this purpose and the validity purpose of noncollaborative evaluations, these four studies have clear implications for non-collaborative studies. The four studies also have implications for SBEs and PPEs, because they point out 
some troublesome oversights in SBE and PPE and suggest methods that collaborative evaluators might wish to consider in future evaluations.

A brief overview of these stakeholder participation studies is given in Table 1. Of the studies, two occurred during the beginning phases of evaluation, when the problems for programs to address are identified (a kind of needs assessment) (Brandon, Newton, \& Harman, 1993) or the attributes of programs to address in evaluation questions are stipulated (Brandon, Lindberg, \& Wang, 1993). The remaining two studies occurred during the ending phases of evaluation, when recommendations for program improvement are prepared (Brandon, in press) or standards for interpreting the extent to which programs have performed satisfactorily are developed (Brandon \& Higa, 1998). ${ }^{4}$ All studies described evaluations of small education programs.

\section{PROCEDURES FOR GUIDING EVALUATOR-STAKEHOLDER INTERACTION}

To tap stakeholders' expertise for the purpose of improving evaluators' understanding of programs (and thereby ultimately enhancing validity), three broad procedural rules (Smith, 1997) were followed in the four studies. The procedures (a) provide guidance for non-collaborative evaluators who seek to involve stakeholders for the purpose of enhancing validity, and (b) suggest revisions that SBE and PPE might make in their approaches to involving stakeholders.

\section{Tapping the Expertise of the Appropriate Group}

The first procedural rule is that the participation of stakeholder groups with the appropriate program expertise should be elicited. These are the groups familiar with the purposes, functions, and operations of the programs; they typically are program personnel such as faculty and staff and program beneficiaries such as students. Together, these groups provide the expertise that evaluators need for fully understanding programs and the evaluation data collected about them.

Program personnel have considerably more knowledge than external evaluators about the program's history, administration, management, and operations. As shown in the summaries of the four studies in Table 1, these stakeholders' expertise can be tapped by involving them in identifying the problems that programs should address (Brandon, Newton, \& Harman, 1993) or in stipulating program attributes that should be evaluated (Brandon, Lindberg, \& Wang, 1993). Both of these activities help evaluators develop better evaluation questions. The expertise of program personnel can also be tapped by having them review evaluators' recommendations for program revisions (Brandon, in press) or having them specify the standards against which to judge performance on program-outcome measures (Brandon \& Higa, 1998).

Program beneficiaries are often familiar with aspects of program implementation or outcomes that neither evaluators nor program personnel know. They should be involved whenever they have this knowledge to contribute, such as in three of the four studies summarized here. In one of these three studies (Brandon. Newton, \& Harman, 1993), the evaluators involved homeless parents (who had been excluded from previous similar studies conducted in nearly every state of the nation) when identifying their children's most severe educational problems. In the second study (Brandon, Lindberg, \& Wang, 1993), the evaluators involved students in helping to identify program attributes to be addressed in a subsequent evaluation. In the third (Brandon, in press), the evaluators involved students in reviewing the evaluators' 


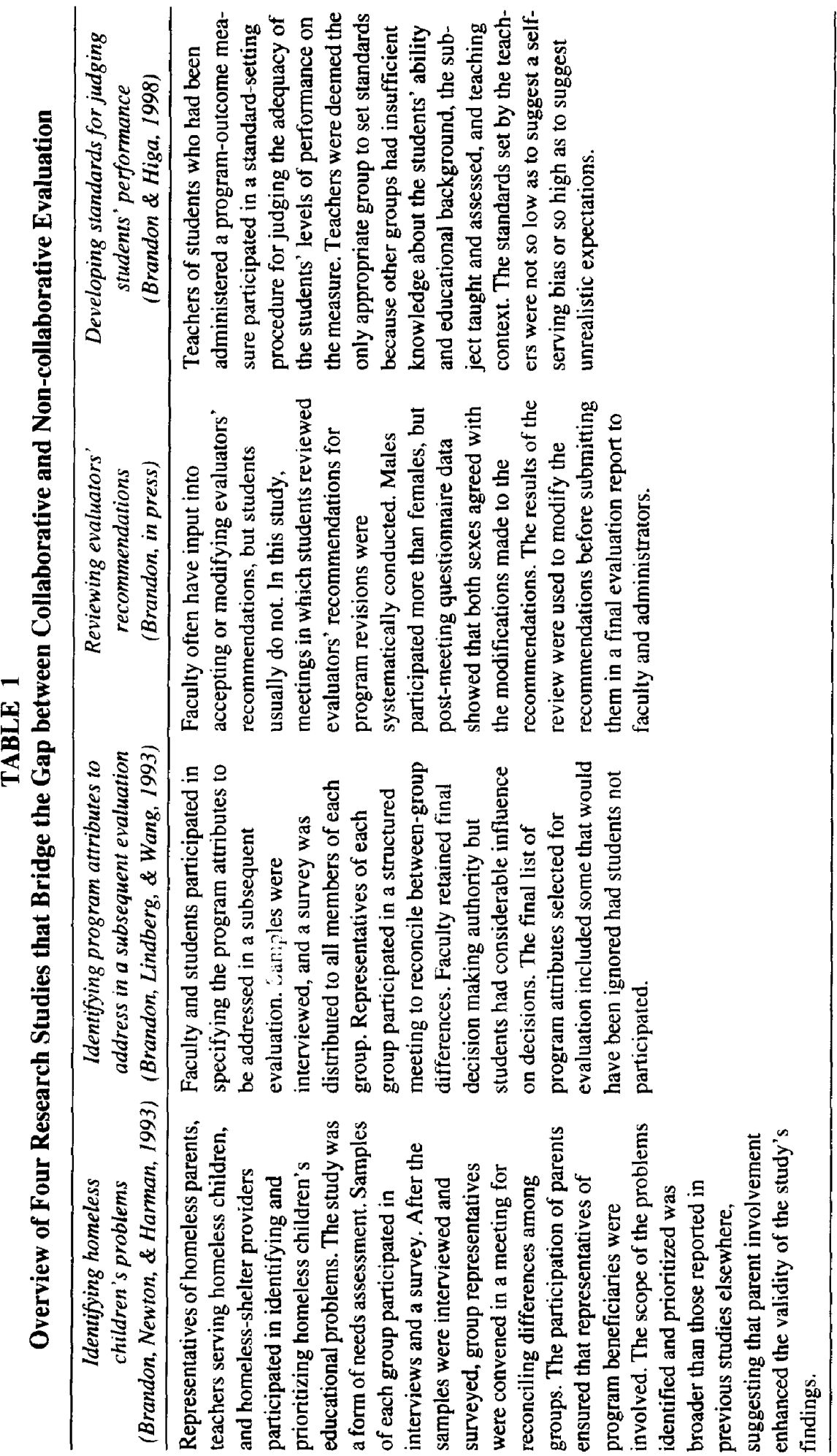


recommendations for program improvement before the recommendations were reported to faculty and administrators. The involvement of program beneficiaries was crucial in these studies because they had relevant information to contribute that program personnel did not know.

Stakeholder groups should participate in program evaluations only if they have the appropriate expertise. For example, when setting standards for judging student performance, the evaluators (Brandon \& Higa, 1998) elicited the assistance of program teachers. Teachers were the only group asked to participate because others had insufficient knowledge about the students' ability and educational background, the subject taught and assessed, and the teaching context. The school principal did not know enough about the capabilities of the assessed students to set fair standards, and parents knew too little about content-area knowledge or skills or about the teaching context to arrive at fair judgments. Setting standards without fully understanding all aspects of schooling can result in standards unfair to the programs.

Beneficiary participation typically is less important to SBE or PPE evaluators than it was to the evaluators in the studies summarized here. No beneficiaries participated in the PPEs included in the volume edited by Cousins and Earl (1995), for example. (Beneficiaries have been involved more in SBEs; for example, see Donmoyer, 1990 and Greene, 1987.) SBE and PPE evaluators often choose not to involve beneficiaries because the primary purpose of such evaluators is to secure the participation of program administrators, managers, and other primary intended users of evaluation findings. As Cousins and Whitmore (1997, p. 6) said about PPE, "Part of the rationale for limiting participation to stakeholders associated closely with program support and management functions is that the evaluation stands a greater chance of meeting the program and organization decision makers' time lines and needs for information."

Without the contribution of program beneficiaries, the validity of SBEs and PPEs might be threatened, resulting in misguided evaluation questions, ill-informed evaluation recommendations, adverse effects for program beneficiaries, or other consequences of evaluation invalidity. A particularly strong risk to validity is cooption of the evaluation by program staff (Dawson \& D'Amico, 1985; see also Perry \& Backus, 1995). As Scriven (1997, p. 170) said about empowerment evaluation, a close cousin of PPE, "It is in the interests of staff . . to make [self-evaluation] results look good, since it is their jobs that are at risk." SBE and PPE evaluators might wish to consider the extent to which they risk these threats to validity and decide if it might be appropriate to include program beneficiaries in their evaluations more frequently.

\section{Tapping Expertise Fully and Carefully}

The second procedural rule followed in the four studies is that stakeholders' program expertise should be fully tapped by applying carefully developed, thorough methods for stakeholder participation. Although not explicitly discussed, this rule has been addressed in a number of published studies of stakeholder participation (e.g., Deutsch \& Malmborg, 1986; Edwards, Guttentag, \& Snapper, 1975; Greene, 1987; Henry, Dickey, \& Areson, 1991; Lawrence \& Cook, 1982; Trochim \& Linton, 1986). ${ }^{5}$

Gleaning stakeholder expertise is a form of data collection that is subject, within reason, to validity requirements. One such requirement is that the instruments for gleaning stakeholder expertise be content valid and of sufficient technical quality. In two of the four studies that are the focus of this article (Brandon, Lindberg, \& Wang, 1993; Brandon, Newton, \& Harman, 1993), a Delphi-like procedure was used in which (a) samples of stakeholders were 
interviewed, the interview results were content-analyzed, and the content-analysis results used to develop a questionnaire, (b) the questionnaires were administered to stakeholder groups (or samples of the groups), and (c) meetings to reconcile the differences among groups' questionnaire results were held with stakeholder representatives. Interviews and survey administration were tailored to the groups (an issue of ecological generalizability). In both studies, scaling methods (Thurstone pair-comparison scaling or magnitude-estimation scaling) were used to analyze questionnaire results. Also, instruments were pilot tested. In one study, content analysis results were supplemented with information obtained in a review of the literature and a review of program documents (Brandon, Lindberg, \& Wang, 1993).

A second validity requirement is that face-to-face decision making among stakeholders should be carefully crafted, organized, and conducted. Efforts to do so were made in all four studies featured here. Brandon, Newton, and Harman (1993) described how evaluators used the Nominal Group Technique to structure stakeholder decision making in a meeting conducted by an experienced facilitator for the purpose of reconciling differences among stakeholder groups. In the second study, Brandon, Lindberg, and Wang (1993) described how evaluators conducted a half-day, tightly-structured meeting (held at a neutral site) of student and faculty representatives, held for the purpose of reconciling differences in their groups' surveyed opinions about the program attributes to address in a subscquent cvaluation. In this study, the evaluators (a) prepared and distributed tables showing the students and faculty their respective groups' survey results, (b) contributed factual information when necessary, (c) gave faculty and students equal opportunity to contribute to the discussion, and (d) summarized the stakeholders' comments on flip-charts throughout the meeting, while ascertaining that all participants understood their content. In the third study, Brandon (in press) showed how evaluators involved students in meetings held to review evaluators' recommendations for program revisions. The evaluators began the meetings with a description of prior instances of successful involvement of similar stakeholder groups. (This step is particularly important with students, who might be recalcitrant about participating if their opinions have routinely been ignored in the past.) In a structured format, an evaluator with experience as a facilitator then presented recommendations to the students. The meetings were brief and convenient, and recommendations were jargonfree, carefully edited, and presented as chart essays, an efficient format useful for oral presentation (as suggested by Torres, Preskill, \& Piontek, 1996). Students' comments were carefully recorded and used to modify several recommendations. Furthermore, participating students believed their involvement had a noteworthy effect on the recommendations. In the fourth study, when K-12 teachers set standards for judging student performance on a program-outcome measure, the evaluators conducted the standard-setting meeting in three rounds (Brandon \& Higa, 1998). In the first round, teachers (who had not yet been given their students' scores) recorded their initial impressions of how well their student groups should have scored. In the second round, teachers reflected on their first-round standards after considering actual distributions of scores for high-scoring schools elsewhere in the district. In the third round, teachers discussed the rationales for the standards they had developed in the first and second rounds; after the discussion, the teachers who saw fit made a final round of revisions to their standards.

The methods for involving stakeholders that are described in the four studies suggest how to glean expertise with care. Regrettably, methods such as these are not emphasized (or at least are not well explicated) in descriptions of SBE or PPE studies (with the exception of the study by Greene, 1987). Indeed, collaborative evaluators often seem to collect information from stakeholders simply by eliciting their contributions in meetings or semi-structured interviews. 
Evaluators conducting SBEs and PPEs might wish to consider adopting methods such as those described in the four studies. These methods help ensure that stakeholder expertise is tapped thoroughly by attending to the details of good information collection, both in formal instruments or data-collection procedures and in structured meetings. The full contribution of stakeholders will help ensure that evaluators can be confident of the validity of the conclusions they draw about programs.

\section{Involving Stakeholders Equitably}

The third procedural rule followed in the four studies is that the equitable participation of stakeholders, both between and within groups, should be ensured. Stakeholders have differential levels of influence on evaluation decisions because of job position and personal characteristics (Bacharach \& Lawler, 1980), particularly when both program staff and program beneficiaries participate in evaluations. Contrary to what we might be led to think by theories of collaborative evaluation, these differences in influence do not go away just because evaluators have declared that they are involving the major stakeholder groups; indeed, unless care is taken to ensure equity, efforts to involve stakeholders in evaluation might actually increase the disparity among groups (Mulder \& White, 1970; O'Neill, 1995).

Although this third procedural rule has overtones of transformative participatory evaluation and other approaches that emphasize stakeholder participation for the purpose of social justice (Cousins \& Whitmore, 1997), the primary intent of the procedure is simply to ensure that no stakeholder groups' expertise is ignored in evaluation decision making. Much of the effort of the evaluators in two of the four studies discussed here was devoted to helping ensure that no stakeholder group's expertise was tapped less than another's. When representatives of homeless parents, social-service providers, and elementary-school teachers participated in identifying the major educational problems of homeless children (Brandon, Newton, \& Harman, 1993), the evaluators included explanations of the purpose of stakeholder participation in the introductions to parent interviews and questionnaires, because parents were inexperienced in need assessments. Interviews of members of all three stakeholder groups took no more than one-half hour each, and questionnaires were brief, thereby helping ensure stakeholders' full participation. Remuneration for completing questionnaires also helped ensure full participation. The evaluators used the Nominal Group Technique, which is designed to ensure equitable group participation, in a meeting to reconcile differences in the survey findings for the three groups. The meeting was small, decreasing the likelihood that any stakeholders would be intimidated. All stakeholder-group representatives attending the meeting had equal access to the evaluation findings. When identifying program attributes to address in a subsequent evaluation (Brandon, Lindberg, \& Wang, 1993), faculty and students had similar opportunities to participate in the interviews and survey. The meeting to reconcile group differences was tightly structured, small, and did not include high-level administrators; equal numbers of faculty and students participated. Faculty representatives were chosen because they were likely to cooperate with students in decision making. Between-group differences in position and personalities were minimized so as to ensure full participation. A trained group facilitator gave all participants in the meeting sufficient opportunities to express their opinions. Faculty retained decision-making authority in the meeting, because they had legal responsibility for curriculum decision making, but students were given considerably more influence than usual in curriculum evaluation. 
Evaluators in the four studies also took steps to help ensure that individual members of stakeholder groups did not dominate the group's input to the evaluation, again for the purpose of ensuring that all participants' expertise could be tapped. When students participated in meetings to review evaluators' recommendations for curriculum revisions in a medicalschool evaluation, for example, the evaluators took steps to ensure that all group members felt they could contribute to the discussions, regardless of gender or personality (Brandon, in press). The meeting facilitator supported equitable discussion by striving to inhibit outspoken participants from dominating the discussions; encouraging clarification, rebuttals, and elaboration by other participants; asking probing questions; and restating students' comments when necessary. Analyses of observation data and of stakeholder questionnaire data collected during the meetings showed that male students tended to participate somewhat more than females, but that both sexes strongly agreed with the suggested revisions to the evaluator's recommendations. Students also reported that they agreed that their participation affected the evaluators' recommendations. When elementary-school teachers participated in a three-part procedure for developing the standards against which to judge student performance on a measure of program outcomes (Brandon \& Higa, 1998), standard setting was conducted in a manner intended to avoid conformity due to social desirability or peer pressure. In the first and second rounds, teachers did not discuss the standards they were setting or the rationales for their standards; in the third round, teachers discussed their rationales without talking about the standards that they had set individually. Training and standard setting were efficient-taking about two hours-thereby helping to ensure teachers' full attention to the standard-setting tasks.

Sometimes program personnel, by virtue of their responsibility for programs, might have more influence than others on the final decisions made in evaluations (Brandon, Lindberg, \& Wang, 1993). However, even in these circumstances, evaluators can take steps to ensure that other groups such as beneficiaries contribute their knowledge and perspectives in an equitable manner before final decisions are made.

Inequity resulting from differences in socioeconomic status is clearly an issue for evaluators to address when they develop methods for involving stakeholders, particularly for the purpose of enhancing validity. Differences in participation due to equity differences among stakeholders has been widely discussed in the evaluation and organizational decision-making literatures (e.g., Donmoyer, 1990; Greene, 1987; House, 1990; Mercurio, 1979; Tjosvold, 1987; Wood, 1989). Descriptions of applications of methods for diminishing inequities in evaluations have not been thoroughly discussed in the PPE or SBE literatures, howevera deficit that should be addressed. Evaluators who are learning how to involve stakeholders should be careful to ensure that differential levels of organizational influence do not adversely affect evaluation validity. Practitioners of PPE and SBE might wish to consider the extent to which their current practices do not sufficiently take these differential levels of stakeholder influence into account. In particular, they might want to avoid adverse social consequences to program beneficiaries (an issue of construct invalidity) that might result from inequitable participation.

\section{CONCLUSION}

A clear conclusion of this article is that stakeholder participation can help enhance the likelihood of producing valid evaluation findings. The strength of this conclusion is stronger than 
it was in any one of the four bridge studies comprising the body of recent research on stakeholder participation, because it is based on a synthesis of these studies. The studies examined stakeholder participation in two tasks in the beginning phase of evaluation and two tasks in the ending phase; together, they support the conclusion that stakeholders can help with a variety of tasks across a breadth of evaluations.

The knowledge that stakeholder participation can enhance validity by increasing evaluators' understanding of programs is important for evaluators who typically have not involved stakeholders extensively in their studies. But the primary original contribution of this article is that this knowledge has implications for collaborative evaluators.

Consider how the purposes of SBE and PPE evaluations have affected methods for stakeholder involvement. The purpose of an evaluation approach tends to determine its procedures (Greene, 1990; Smith, 1995, 1997). The SBE and PPE purpose of enhancing program personnel's use of evaluation findings is likely to incline evaluators toward collecting stakeholder information in unstructured interviews or during informal interactions with stakeholders as fellow members of evaluation teams. These methods are appropriate for gathering information that serves the social role of ensuring the use of evaluative findings.

In contrast, consider how the purpose of enhancing validity affects the selection and development of methods for involving stakeholders. The evaluators in the four studies described in this article applied a repertoire of methods from psychometrics and social-science research when they collected information from stakeholders for the purpose of enhancing validity. Methods were developed or selected to collect information in a thorough and equitable manner from all appropriate stakeholder groups. They were appropriate for the role of helping assure evaluation clients of the soundness of evaluation findings.

If SBE and PPE evaluators were to broaden their purposes to include involving stakeholders for enhancing validity, they would be more likely to adopt methods such as those shown in the four studies. By taking greater care to involve all appropriate stakeholder groups and to apply methods that collect stakeholder information fully and equitably, SBE and PPE evaluators would be informed more fully. Such efforts would improve the credibility of their studies. Collecting stakeholder information equitably and fully would require more evaluation resources, but, as the risk of threats to validity was diminished, evaluation conclusions would be strengthened.

Focusing on validity does not mean that the use of evaluation findings must be ignored. Just as in collaborative evaluations, it is likely that the use of evaluation findings was enhanced in the four studies described in this article, because stakeholders participating in the evaluations were involved during significant steps and in influential ways. Decision makers such as administrators who were not directly involved in the evaluations (because they did not have the type of expertise that the evaluators needed to tap) were more likely to heed evaluation conclusions because they knew that their staff members had been involved in significant phases of the evaluation.

In summary, this article can serve as a guide for structuring interactions with stakeholders during the beginning and ending phases of evaluations. By tapping the expertise of all appropriate stakeholder groups and by using methods to glean this expertise fully and equitably, evaluators can take steps calculated to enhance evaluation validity. Evaluators' confidence in the credibility of their studies should be improved, and, most likely, they will find that their studies will receive greater use. 


\section{AUTHOR NOTE}

This article is a revised version of a paper presented at the meeting of the American Evaluation Association, San Diego, CA, November 1997. The author is grateful to Nick Smith and Brad Cousins for their reviews of the conference version of this manuscript and to two anonymous reviewers for their helpful comments about the current version. The author also thankfully acknowledges the contributions of James Harman, Terry Ann Higa, Barbara Newton, Marlene Lindberg, and Jonathan Wang to the development and implementation of the evaluations discussed in the four studies synthesized in this article.

\section{NOTES}

1. Practical participatory evaluation should be distinguished from transformative participatory evaluation (Cousins \& Whitmore, 1997), which is not discussed here because its purposes (primarily ideological and political) are different from those of PPE.

2. Most discussions of validity in the program evaluation literature have focused on evaluation designs, addressing issues of external and internal validity (e.g., Cook, 1991). Even when construct validity recently was explicitly discussed in this literature, the focus was on validity within the context of experimental and quasi-experimental design (Conrad \& Conrad, 1994).

3. This term was suggested to me by Robert W. Heath.

4. This article focuses on four studies which discuss stakeholder participation during the beginning and ending phases of evaluations because stakeholder participation is most important in these phases of evaluations, when purpose is established or conclusions are drawn. It could also legitimately focus on stakeholder participation in the middle phase, when evaluation instruments are developed and data are collected and analyzed, because stakeholders' contributions in this phase can obviously also help enhance validity.

5. However, the methods described in some of these studies are not fiscally feasible for the evaluation of small education programs such as those described in this article.

\section{REFERENCES}

Bacharach, S. B., \& Lawler, E. J. (1980). Power and politics in organizations. San Francisco: JosseyBass.

Brandon, P. R. (in press). Involving program stakeholders in reviews of evaluators' recommendations for program revisions. Evaluation and Program Planning.

Brandon, P. R., and Higa, T. A. F. (1998, April). Setting standards to use when judging program performance in stakeholder-assisted evaluations of small educational programs. Paper presented at the meeting of the American Educational Research Association, San Diego, CA.

Brandon, P. R., Lindberg, M. A., \& Wang, Z. (1993). Involving program beneficiaries in the early stages of evaluation: Issues of consequential validity and influence. Educational Evaluation and Policy Analysis, 15, 420-428.

Brandon, P. R., Newton, B. J., \& Harman, J. W. (1993). Enhancing validity through beneficiaries' equitable involvement in identifying and prioritizing homeless children's educational problems. Evaluation and Program Planning, 16, 287-293.

Bryk, A. (1983). (Ed.), Stakeholder-based evaluation: New directions for program evaluation 17. San Francisco: Jossey-Bass. 
Carey, M. A., \& Smith, M. W. (1992). Enhancement of validity through qualitative approaches: Incorporating the patient's perspectives. Evaluation and the Health Professions, 15(4), 107-114.

Conrad, K. J., \& Conrad, K. M. (1994). Reassessing validity threats in experiments: Focus on construct validity. In K. J. Conrad (Ed.), Critically evaluating the role of experiments: New Directions for Program Evaluation 63 (pp. 5-25). San Francisco: Jossey-Bass.

Cook, T. D. (1991). Clarifying the warrant for generalized causal inferences in quasi-experimentation. In M. W. McLaughlin \& D. C. Phillips (Eds.), Evaluation and education: At quarter century. Ninetieth yearbook of the National Society for the Study of Education, Part II (pp. 115-144). Chicago: National Society for the Study of Education.

Cousins, J. B., Donohue, J. J., \& Bloom, G. A. (1996). Collaborative evaluation in North America: Evaluators' self-reported opinions, practices and consequences. Evaluation Practice, 17, 207-226.

Cousins, J. B., Donohue, J. J., \& Bloom, G. A. (1997, November). Dimensions of form of collaborative evaluation as predictors of utilization. Paper presented at the annual meeting of the American Evaluation Association, San Diego, CA.

Cousins, J. B., \& Earl, L. M. (1992). The case for participatory evaluation. Educational Evaluation and Policy Analysis, 14, 397-418.

Cousins, J. B., \& Earl, L. M. (Eds.). (1995). Participatory evaluation in education: Studies in evaluation use and organizational learning. Washington, D.C.: Falmer.

Cousins, J. B., \& Whitmore, E. (1997, May). Framing participatory evaluation. Paper presented at the annual meeting of the Canadian Evaluation Society, Ottawa.

Dawson, J. A., \& D'Amico, J. J. (1985). Involving program staff in evaluation studies: A strategy for increasing information use and enriching the data base. Evaluation Review, 9, 173-188.

Deutsch, S. J., \& Malmborg, C. J. (1986). A study on the consistency of stakeholder preferences for different types of information in evaluating police services. Evaluation and Program Planning, 9, 13-24.

Donmoyer, R. (1990). Curriculum evaluation and the negotiation of meaning. Language Arts, 67, 274286.

Edwards, E. L., Guttentag, M., \& Snapper, K. (1975). A decision-theoretic approach to evaluation research. In E. L. Struening \& M. Guttentag (Eds.), Handbook of evaluation research (pp. 139181). Beverly Hills, CA: Sage.

Glaser, R., \& Chi., M. T. H. (1988). Introduction: What is it to be an expert? In M. T. H. Chi, R. Glaser, \& M. J. Farr (Eds.), The nature of expertise (pp. xv-xxiix). Hillsdale, NJ: Lawrence Erlbaum.

Greene, J. C. (1987). Stakeholder participation in evaluation design: Is it worth the effort? Evaluation and Program Planning, 10, 379-394.

Greene, J. C. (1990). Technical quality versus user responsiveness in evaluation practice. Evaluation and Program Planning, 13, 267-274.

Henry, G. T., Dickey, K. A., \& Areson, J. C. (1991). Stakeholder participation in educational performance monitoring systems. Educational Evaluation and Policy Analysis, 13, 177-188.

Hoffman, R. R. (1994). (Ed.), The psychology of expertise: Cognitive research and empirical AI. New York: Springer-Verlag.

House, E. R. (1990). Trends in evaluation. Educational Researcher, 19(3), 24-28.

Huberman, M, \& Cox, P. (1990). Evaluation utilization: Building links between action and reflection. Studies in Educational Evaluation, 16, 157-179.

Joint Committee on Standards for Educational Evaluation. (1994). The program evaluation standards (2nd ed.). Thousand Oaks, CA: Sage.

Lawrence, J. E. S., \& Cook, T. J. (1982). Designing useful evaluations: The stakeholder survey. Evaluation and Program Planning, 5, 327-336.

Mercurio, J. A. (1979.) Community involvement in cooperative decision making: Some lessons learned. Educational Evaluation and Policy Analysis, 1(6), 37-46.

Messick, S. (1989). Validity. In R. L. Linn (Ed.), Educational measurement (3rd ed.) (pp. 13-103). New York: American Council on Education/Macmillan. 
Messick, S. (1995). Validity of psychological assessment: Validation of inferences from persons' responses and performances as scientific inquiry into score meaning. American Psychologist, 50, 741-749.

Mulder, M., \& Wilke, H. (1970). Participation and power equalization. Organizational Behavior and Human Performance, 5, 430-448.

O'Neill, T. (1995). Implementation frailties of Guba and Lincoln's fourth generation evaluation theory. Studies in Educational Evaluation, 21, 5-21.

Owston, R. D. (1986). Establishing validity in evaluation: The Canadian Indian school evaluations. Evaluation and Program Planning, 9, 319-323.

Perry, P. D., \& Backus, C. A. (1995). A different perspective on empowerment in evaluation: Benefits and risks to the evaluation process. Evaluation Practice, 16, 37-46.

Rogers, W. T. (1995). The treatment of measurement issues in the revised Program Evaluation Standards. Journal of Experimental Education, 61, 13-28.

Scriven, M. (1997). Empowerment evaluation examined. Evaluation Practice, 18, 165-175.

Shanteau, J. (1988). Psychological characteristics and strategies of expert decision makers. Acta Psychologica, $68,203-215$.

Shepard, L. A. (1993). Evaluating test validity. In L. Darling-Hammond (Ed.), Review of research in education (Vol. 19, pp. 405-450). Washington, DC: American Educational Research Association.

Smith, N. L. (1983). Citizen involvement in evaluation: Empirical studies. Studies in Educational Evaluation, 9, 105-117.

Smith, N. L. (1995). The influence of societal games on the methodology of evaluative inquiry. In D. M. Fournier (Ed.), New Directions for Evaluation 44 (pp. 5-14). San Francisco: Jossey-Bass.

Smith, N. L. (1997, November). An investigative framework for characterizing evaluation practice. In N. L. Smith (Chair), Examining Evaluation Practice. Symposium conducted the meeting of the American Evaluation Association, San Diego, CA.

Tjosvold, D. (1987). Participation: A close look at its dynamics. Journal of Management, 13, 739-750.

Torres, R. T., Preskill, H. S., \& Piontek, M. E. (1996). Evaluation strategies for communication and reporting: Enhancing learning in organizations. Thousand Oaks, CA: Sage.

Tovar, M. (1989). Representing multiple perspectives: Collaborative-democratic evaluation in distance education. The American Journal of Distance Education, 3(2), 44-56.

Trochim, W. M. K., \& Linton, R. (1986). Conceptualization for planning and evaluation. Evaluation and Program Planning, 9, 289-308.

Wood, C. J. (1989). Challenging the assumptions underlying the use of participatory decision-making strategies. Small Group Behavior, 20, 428-448. 